\title{
Facilitation of nursing students' competency acquisition for paediatric pain management in low- and middle-income countries: a scoping review
}

\author{
Uwimana P. ${ }^{1}$, Mukamana D. ${ }^{1}$, Adejumo O. ${ }^{1,2}$, Babenko-Mould Y., Umubyeyi B. ${ }^{1}$
}

\begin{abstract}
Objective: To elucidate evidence regarding nurse educators' and preceptors' capacity to facilitate students' learning about paediatric pain management (PPM) in low- and middle-income countries (LMICs).

Methods: The five-stage framework by Arksey and O'Malley guided this review. Studies published in English between January 2010 and April 2020 were searched using EBSCO Host/ ScienceDirect, CINAHL, MEDLINE, PUBMED and Scopus. Of 300 papers identified through the search strategy 27 primary research articles were retained: quantitative $(n=18)$, qualitative $(n=8)$ and mixed-methods $(n=1)$.
\end{abstract}

Results: Knowledge deficiency and inappropriate attitudes toward PPM, lack of autonomy in decisionmaking, scarcity of resources and cultural misconception regarding pain in children were hindering the effective PPM in LMICs. Strategies including nursing curricula review, continuous in-service training, access to resources and the leadership support are required to optimise effective PPM and improve students' facilitation for learning about PPM.

Conclusion: Further research is required as a body of evidence to support the development of a framework for capacity enhancement of nurse educators and nurse preceptors who facilitate nursing students acquiring competency for PPM in LMICs.

Keywords: Pain management education, Children, Scoping review, Low- and middle- income countries

*Corresponding author:

Uwimana P.

Email:philouwim@gmail.com; uwimphilo@yahoo.fr

${ }^{1}$ School of Nursing and Midwifery, College of Medicine and Health Sciences, University of Rwanda, Kigali, Rwanda

${ }^{2}$ Rory Meyers College of Nursing, New York University, New York, United States of America

${ }^{3}$ Arthur Labatt Family School of Nursing, Western University, London, Ontario, Canada

Research Journal of Health Sciences subscribed to terms and conditions of Open Access publication. Articles are distributed under the terms of Creative Commons Licence (CC BY-NC-ND 4.0). (http://creativecommons.org/licences/by-nc-nd/4.0).

http://dx.doi.org/10.4314/rejhs.v9i1.10 


\title{
Facilitation de l'acquisition des compétences des étudiants en soins infirmiers pour la gestion de la douleur pédiatrique dans les pays à revenu faible et intermédiaire : un examen de la portée
}

\author{
Uwimana P. ${ }^{1}$, Mukamana D. ${ }^{1}$, Adejumo O. ${ }^{1,2}$, Babenko-Mould Y. ${ }^{3}$, Umubyeyi B. ${ }^{1}$
}

\section{Résumé}

Objectif de l'étude : Elucider les preuves concernant la capacité des infirmières enseignantes et des précepteurs à faciliter l'apprentissage des étudiants sur la gestion de la douleur pédiatrique (GDP) dans les pays à revenu faible et intermédiaire (PRFI).

Méthode de l'étude: Le cadre en cinq étapes d'Arksey et O'Malley a guidé cet examen. Les études publiées en anglais entre janvier 2010 et avril 2020 ont été recherchées à l'aide d'EBSCO Host/Science Directe, CINAHL, MEDLINE, PUBMED et Scopus. Sur 300 articles identifiés grâce à la stratégie de recherche, 27 articles de recherche primaire ont été retenus: quantitatifs $(n=18)$, qualitatifs $(n=8)$ et méthodes mixtes $(\mathrm{n}=1)$.

Résultat de l'étude: Les connaissances, les lacunes et les attitudes inappropriées à l'égard de la PPM, le manque d'autonomie dans la prise de décision, la rareté des ressources et les idées fausses culturelles concernant la douleur chez les enfants entravaient l'efficacité de la GDP dans les PRFI. Des stratégies comprenant la révision des programmes de sciences infirmières, la formation continue, l'accès aux ressources et le soutien du leadership est nécessaire pour optimiser l'efficacité de la GDP et améliorer la facilitation des étudiants à apprendre la GDP.

Conclusion: Des recherches supplémentaires sont nécessaires en tant que corpus de données probantes pour soutenir l'élaboration d'un cadre pour le renforcement des capacités des infirmières enseignantes et des infirmières préceptrices qui aident les étudiants en sciences infirmières à acquérir des compétences pour la GDP dans les PRFI.

Mots-clés: Éducation à la gestion de la douleur, enfants, examen de la portée, pays à revenu faible et intermédiaire

*Corresponding author:

Uwimana P.

Email :philouwim@gmail.com; uwimphilo@yahoo.fr

${ }^{1}$ School of Nursing and Midwifery, College of Medicine and Health Sciences, University of Rwanda, Kigali, Rwanda

${ }^{2}$ Rory Meyers College of Nursing, New York University, New York, United States of America

${ }^{3}$ Arthur Labatt Family School of Nursing, Western University, London, Ontario, Canada 


\section{INTRODUCTION}

Numerous studies have consistently reported that pain in children is poorly managed by nurses through inadequate assessment of the pain, under medication for pain and their unpreparedness to address various types of pain in the paediatric population $(1,2)$. This occurs despite studies highlighting that improper pain management has the potential for lasting negative outcomes for patients (3). To prevent the complications relating to unrelieved pain, previous evidence indicates that it is important to perform an effective assessment of the child's pain, which guides proper diagnosis and appropriate interventions for pain relief (4). Twycross and Williams (2014), suggested four stages of optimal pain management in children which include assessing child's pain, selecting appropriate pain-relieving interventions that may be pharmacological or non- pharmacological interventions, implementing pain-relieving interventions, and evaluating the effectiveness of the interventions (5).

The literature on education about pain management shows that nurses and nursing students exhibit knowledge deficits and lack of confidence for children's pain management. A study that aimed to assess final year nursing students' knowledge and attitudes about paediatric pain showed that under medication was a common issue as a result of lack of knowledge, fear of patient addiction, and inadequate assessment skills (6). Similarly, authors have reported that undergraduate nursing students had a knowledge deficit in the area of pain management and that there was a need to develop specific teaching strategies and more educational materials to enhance their knowledge base about paediatric pain management (PPM) (7-9).

Undergraduate nursing education programs are foundational to support students in their development of clinical competencies for PPM so that they may provide quality paediatric care as nurses upon graduation. If students are not provided with an opportunity to develop PPM competencies, their paediatric clinical practice would be negatively impacted, which could ultimately translate to ineffective care delivery. As such, it is proposed that nurse educators should significantly contribute to addressing the topic of PPM by facilitating students' acquisition and utilization of associated clinical competencies $(10,11)$. Lasch and colleagues stated that competent educators and clinical mentors were a valuable source to enable students' learning about pain management principles and that they influenced the quantity and quality of information students were receiving (11). Thus, academics and clinical practice partners play an essential role in facilitating students' achievement of intended learning outcomes during students' paediatric theory-based course work and clinical learning experiences (12-15).

While existing literature mainly focused on nurses' competencies for PPM in clinical practice, there is a paucity of evidence about undergraduate nursing students' competencies and PPM, or factors influencing the facilitation of students' acquisition of PPM competencies by nurse educators during students' pre-licensing programs. In addition, the limited literature that exists on the topic is mostly from western countries (16-19). To the best knowledge of the authors, there is paucity of literature review conducted in low- and middle-income countries (LMIC) around the facilitation of nursing students to learn effectively, in classroom and clinical placements, about PPM during undergraduate training.

A scoping review of the literature was conducted to map the PPM education literature in the context of nurse educators' and preceptors' capacity to facilitate students' learning about PPM. The aim was to elucidate what is known, as well as highlight gaps in research about the facilitation of nursing students' competency acquisition for PPM by nurse educators and preceptors.

\section{MATERIALS AND METHODS}

The scoping review was guided by the framework outlined by Arksey and O'Malley (2005), which includes five stages: identification of the research question, identification of relevant studies, selection of studies for review, charting the data, collating, summarising, and reporting the results. The optional consultation stage (20), was not taken into account in the current review.

\section{Identifying the research question}

The questions guiding this paper reflect the aim of the review, and included: what exists in the literature about PPM competencies taught to nursing students?, what are the gaps in those PPM competencies?, what are the factors that influence the capacity of nurse educators and preceptors to facilitate students' learning about PPM?, and what are the strategies to improve the capacity of nurse educators and preceptors to facilitate students' competency acquisition about 
PPM? A greater understanding of issues regarding the capacity of nurse educators and preceptors to facilitate students' learning about PPM in LMICs may lead to improved education outcomes with the potential to ultimately improve healthcare provision to paediatric patients.

\section{Identifying relevant studies}

A literature search was conducted using databases including EBSCO Host/ ScienceDirect, CINAHL, MEDLINE, PUBMED and Scopus. References were scanned and manual searching was conducted for additional relevant publications. Keywords and $\mathrm{MeSH}$ terms were used to search for relevant publications. The search terms identify existing information resources in the databases where synonyms and combinations using Booleans operators (AND/OR) were used to include or exclude terms. The following terms were searched in the titles and /or abstracts: "nurse educators" or "nursing faculty"; "preceptor" or "clinical nurse"; "paediatric" or "pediatric" or "child"; "pain management" or "pain relief" or "pain control"; "competency" or "competence" or "knowledge and attitudes"; "competency acquisition"; "pain education"; "teaching"; "nursing students"; "developing country" or "low- and middle-income countries". To determine the scope of this review relating to low- and middle- income economies, countries defined as such by the World Bank (21) were included in the search. The search was limited to articles written in English and published between January 2010 and April 2020.

\section{Inclusion and exclusion criteria}

Articles were included for the review if they met the following inclusion criteria: (1) the study specifically described participants as nurses (educators, preceptors/ clinical nurse) or nursing students, or these participants were separately analysed if other health care professionals were included; (2) quantitative and/or qualitative information on paediatric pain management education described; (3) the study reported information from an LMIC setting. Published studies were excluded if their focus was not PPM or did not examine paediatric pain education in nurses.

Studies selection was done through screening at the level of titles, abstracts, and full texts. The first elimination concerned the removal of duplicate titles, followed by selecting only abstracts' relevant to the research questions.

\section{Data Charting}

Information from the selected studies was organised and recorded using a template that included the following key areas to be used as data: Author(s) and year of publication, country or region where the study was conducted, the aim of the study, participants/ sample size, study design/ methods, key findings/ conclusion (Table1).

\section{Collating, summarising, and reporting the results.}

The extracted information was summarized and analysed using content analysis to identify descriptive themes that would contribute to addressing the scoping review questions.

\section{RESULTS}

A total of 288 papers were found through the initial search strategy in the aforementioned databases and 12 additional papers were located from a manual scan of references. After removing duplicate papers and further screening of titles and abstracts, 44 full text published articles were retained as potentially relevant, of which 27 papers ultimately met the inclusion criteria (Figure 1).

\section{Description of the included studies}

Out of 27 primary research articles retained, $66.7 \% \%(\mathrm{n}=18)$ were classified as studies using quantitative methods, $29.6 \%(\mathrm{n}=8)$ were qualitative exploratory descriptive studies, and $3.7 \%(\mathrm{n}=1)$ used a mixed-methods approach. Journal articles represented the majority of the included studies $(n=24)$, the remainder were theses $(\mathrm{n}=2)$, and a conference proceeding $(\mathrm{n}=1)$. Geographically, most of the studies were conducted in the African region (40.8\%), Eastern Mediterranean region $(22.2 \%)$, the region of South-Eastern Asia (22.2\%) and the region of the Americas (14.8\%).

Of these, 16 studies evaluated the competency for PPM among nurses and nursing students $(6,9,22-34)$, eight explored factors impacting PPM by nurses (26,35-41), four studies evaluated the effect of educational programs for nurses on improving pain management in children $(12,34,42,43)$, one explored the capacity of nurse educators and preceptors to facilitate nursing students knowledge development about PPM (44), one studied educational needs of nurses on paediatric units (45). Twenty-two (22) studies included nurses in clinical settings as study participants, 6 
studies involved nursing students, 4 studies involved multidisciplinary healthcare professionals including nurses, and 1 study involved nurse educators (faculty and clinical instructors) and nurse preceptors.

\section{Competencies for paediatric pain management among undergraduate nursing students}

Five studies used the Paediatric Nurses' Knowledge and Attitudes Survey for pain (PNKAS) to assess the competency of nursing students for PPM $(6,9,25,27,29)$. In these studies, the mean scores for PNKAS were less than $50 \%$ ranging from $18.36 \%$ (7) to $44 \%$ (6), and more than three-quarters of nursing students scored less than $50 \%$ to the PNKAS $(9,25)$, indicating unsatisfactory knowledge and attitudes towards PPM. Another study used a pain management knowledge questionnaire to determine intern nursing students' level of PPM knowledge, which revealed an achieved mean score of $65.61 \%$. Also, $63.9 \%$ of student participants selfevaluated their current knowledge as inadequate (32). Although generally, nursing students demonstrated poor knowledge and attitudes towards PPM, studies reported that students had a good understanding that pain is a subjective experience $(6,9,25,27,29)$, the physiopathology of pain $(9,34)$, and the benefits of giving a preemptive treatment of pain to children with the repeated painful procedure $(6,9,25,27)$. Also, in two studies, students exhibited sufficient knowledge and good attitudes regarding pain self-report in children less than 8 years of age for pain assessment $(6,32)$.

Major areas of concern reported in the reviewed studies were related to competencies for pharmacologic management of pain where students were determined to have poor knowledge about the recommended route of administration of opioid analgesics $(24,29)$, potentially useful pain medications $(6,27)$, and pain medication adverse effects $(9,25,29)$. Also, knowledge gaps for non-pharmacologic PPM was reported $(6,25)$. Similarly, knowledge deficits and inappropriate attitudes were reported about issues concerning paediatric pain assessment such as underestimation of pain, such as in the case of a patient who smiles despite rating his pain at $8,(6,9,25,27)$ or inaccurate perceptions about patients who were perceived as over-reporting about their pain $(6,25,27,29)$.
Factors influencing the capacity of nurse educators and preceptors to facilitate nursing students' competency acquisition for PPM

There is a dearth of literature on the capacity of nurse educators and preceptors to facilitate nursing students' competency acquisition for PPM in LMICs. Only one (1) study explored the capacity of nurse educators and preceptors to facilitate nursing students learning PPM (44). The study reported that the capacity of educators and preceptors to facilitate students depended on their own competencies for PPM acquired from training on that matter or from clinical experience in caring for paediatric pain patients (44).

The scoping review gathered studies that reported factors influencing the effective paediatric management of pain in clinical settings and that could implicitly impact on the competency acquisition by nursing students when they join clinical settings for their practical learning about PPM.

\section{Factors facilitating effective PPM}

One study examined the facilitators of effective pain management in children (38).

Involvement of patients and parents in the diagnosis and pain relief: Parents' participation in the care reinforces their cooperation and assistance in the assessment and control of pain in children as they perform nonpharmacologic pain control interventions, while participation of children in reporting is dependent to their level of maturity and how their consciousness is affected (38).

Timely provision of care: The easy and timely access to the medical team was seen as an accelerator for pain relief; the presence of healthcare providers and parents or caregivers at the paediatric patient's bedside was considered as emotional support and a facilitator in dealing with patient expressions of pain (38)

Proper communication: The researchers mentioned that a well-established rapport between the medical and nursing staff and the parents or caregivers involved in the care of the paediatric patient promoted optimal pain management (38) Also, proper communication and counselling might help patients and their families cope with distress caused by pain.

Education and supportive role of nurses: The study indicated that as nurses explain the adverse effects of analgesics and teach parents or caregivers about non-pharmacologic techniques for pain relief, they fulfil their education and supportive role (38). When nurses provide 
relevant information to the paediatric patient and their parents/caregivers, the parents/caregivers can potentially feel a release from the anxiety surrounding the paediatric pain experience and become more involved in the child's pain management plan. Also, nurses emotionally support by touching and cuddling the child, and using words aiming at the reassurance of the child experiencing pain (38).

\section{Factors hindering effective PPM}

Competency deficit for PPM: Inadequate competency for nursing staff was the most frequently cited issue in the studies that reported on barriers to effective PPM (22,23,26,29-31,35$37,39-41,45)$, and also of nurse educators (44) Due to the inadequate pre-licensing or lack of inservice training that resulted in a deficit in knowledge and lack of confidence, nurses had difficulty in assessing pain in children as they did not know how to use pain assessment tools $(26,29,37)$, or to assess pain for children with unfunctional communication $(37,45)$. Also, findings from the studies revealed poor knowledge and inadequate attitudes among nurses for pharmacological and nonpharmacological paediatric pain management with the most concerns related to the fear of administering opioids because of adverse effects $(21,26,28,29,33,41)$, doses and dosages for children according to their developmental milestones (43). Additionally, lack of training about paediatric pain and pain management resulted in misconceptions about the experience of pain in children, as some nurses felt that children perceive less pain than adults which hampered their assessment of pain in paediatric patients $(22,23,29,35)$. One study suggested that knowledge and attitude gaps towards PPM were due to lack of support from supervisors that could help nurses link theory with practice (28).

Lack of autonomy for decision making regarding pain management: Factors related to lack of authority and professional autonomy for decision making regarding patient care were mentioned in four studies $(28,37,39,40)$. In Malawi, it was indicated that older and more experienced nurses had influence over younger nurses regarding morphine administration as the more experienced thought that by administering it the newer nurses would facilitate death in a child (28). Nurses in Indonesia and Ghana felt powerless because of the cultural organization that promotes medical dominance over nurses; they voiced they were lacking the authority of prescribing analgesia to suffering children and were not working collaboratively in decision-making for patient pain management plans $(39,40)$. In Iran, nurses mentioned their poor involvement in clinical decision-making regarding selection of painrelief practices and limited autonomy in performing their tasks to relieve pain (39), all of which impeded on the quality of care they provided to the children in pain.

Scarcity of resources: Insufficient nursing staff: Six studies reported about how poor staffing in paediatric units lead to a burden-filled workload, challenging the effective management of pain in hospitalised children (31-33,35-37). The shortage of nursing staff and the time demands of some non-pharmacological pain management techniques hampered the optimal management of pain $(33,37)$.

Lack and/or inaccessibility of essential pain medication: The challenges around accessibility of essential pain medications was reported in two studies $(39,41)$. A descriptive qualitative study explored the experience of nurses' barriers to pain management in paediatric units in Iran. They found that accessibility to opioids was challenging due to slow administrative and organizational structure that hampered the PPM process (39). Another qualitative study that explored the barriers faced by health professionals for paediatric pain control in Sub-Saharan Africa (SSA) highlighted how lack of essential pain medications and a fear of using morphine was contributing to underreporting and under-treatment of paediatric pain (41).

Scarcity of equipment to assess and manage paediatric pain: In six studies, unavailability of resources such as assessment tools, clinical guidelines, and protocols for pain assessment and pain management was perceived as a barrier for nurses' optimal management of pain $(26,28,36,37,39,40)$. Further, the dearth of pain assessment scales impeded nurses' knowledge about how to use those scales (28)) and nurses suboptimal pain assessment behaviours were attributed to the absence of pain assessment tools in the children's units (36).

Child and parent/caregiver characteristics: Four studies reported that individual characteristics of the child and or caregiver were impediments during the care provision $(28,37,39)$. Nurses stated that pain assessment was challenging in pre-verbal children and children with impaired communication (28,37). Apart from her/his ability to communicate, it was also reported that the child's mood, age and previous experience of pain are characteristics that influence PPM (39). 
Also, nurses indicated that some parents'/ caregivers' characteristics such as lack of knowledge for non- pharmacologic pain management interventions, parental experience and their mood could be barriers to PPM (39).

Cultural beliefs: Two studies reported the influence of the culture on PPM $(31,41)$. In one study, the authors indicated that nurses considered that stoicism was encouraged in children and viewed it as a belief that could interfere with the assessment of pain in children (31). Another study that explored the barriers for paediatric pain control in SSA indicated that the context of cultural perceptions and beliefs surrounding suffering and healing hampers the optimal management of pain in children. An example was about parents seeking traditional healing for the child and the consequences this creates. The authors recognized that, for a better understanding of the barriers to children's pain management in SSA, it was fundamental to consider how pain is perceived by children, parents, and healthcare professionals (41).

Strategies for improving the capacity of nurse educators and preceptors facilitating students' competency acquisition for PPM Enriching curriculum of the undergraduate nursing program: A revision of existing curriculum in undergraduate nursing education to enrich it about PPM was highlighted in five studies $(6,9,12,25,44)$. Authors indicated that there was a real need to put more emphasis on PPM in the curriculum content, as well as the use of educational interventions such as nursing skills lab that support knowledge translation into practical skills $(6,27)$, and online interactive educational programme for teaching/ learning about PPM (12). Furthermore, the acquired competencies need to be reinforced in paediatrics wards of clinical settings (44).

Continuing in-service education: Investing in continuing in-service education for nurses about PPM was reported in ten studies $(12,22,24,28$ $30,34,36,42,43)$. Studies that evaluated the effect of educational programs indicated that repeated education sessions enable the reinforcement of knowledge and skills for pain management, that ultimately contributes to improved quality nursing care provided to suffering children $(12,22,34,43)$. Following education about pain management, nurses were eager to educate themselves and improve their knowledge of PPM (43). In another study, it was emphasized that the transformation of knowledge about PPM into improved nursing care requires reinforcement of knowledge of pain and management strategies that are provided by nurse educators and mentors (36). Because the culture influences people's beliefs about experiences with pain and their decision for seeking pain management, whereas educating nurses using evidence based practice might be challenging, one study mentioned that nurses need to learn about culturally acceptable pain management approaches (43).

Two studies considered interventional studies as a good strategy to develop and implement targeted solutions to nurses' identified needs $(25,45)$. For instance in Egypt, intervention studies were thought for preparing newly graduated nursing students how to integrate their theoretical knowledge about pain into clinical practice for pain management (25), whereas in Ghana, it was stated that interventions studies might guide the development, implementation and evaluation of short-course programs on PPM tailored on nurses' educational needs (45).

Securing appropriate resources: Nurses should be empowered and supported with the requisite material resources such as appropriate and userfriendly pain assessment tools, guidelines and standards for effective management of children's pain (19). The availability of equipment and the provision of a conducive physical environment by the managers, and considering the high shortage of nursing personnel in paediatric units were mentioned as critical for optimal nursing $\operatorname{PPM}(31,39)$.

Leadership support and Structure reorganization: For addressing pain care needs in children and their families, three studies indicated that it was fundamental to promote nursing competencies by responding to nurses PPM educational needs, create opportunities for supportive supervision for nurses in clinical settings, promote collaborative practices among healthcare professionals $(28,39,45)$. A study conducted in Malawi suggested that to address the issue on the use of pain assessment scales, nurses should be educated and demonstrated on their use, and also facilitated by their direct supervisors to link the theory and practice (28), while another study in Ghana reported that leadership support was essential in improving pain outcomes in children, commending the involvement of nurse managers to address the educational needs of nurses (45). Additionally, the study suggested considering modifying the organisational structure of health care professionals to boost nurses' autonomy in assessing and managing pain in the paediatric patient. The involvement in the decision-making 
regarding pain relief practices empowers nurses and might promote collaborative practice needed for easing patients' pain, instead of waiting for doctors' instructions and orders (39).

Figure 2 summarizes the findings of this scoping review regarding the competency of nursing students for PPM, the factors that influence the facilitation of nurse educators and preceptors for nursing students learning PPM, and strategies to improve the ability of nurse educators and preceptors helping students to learn PPM.

\section{DISCUSSION}

The review included 27 studies on PPM conducted in different LMICs in Africa, Asia, the Middle East, and Latin America. Methodologically, quantitative approaches were used in the majority $(66.7 \%)$ of the reviewed studies, and mostly for assessing the competency of nurses and nursing students for PPM, 29.6\% used qualitative methods to collect and analyse the data on factors influencing PPM and /or facilitation of students' learning PPM, while in the remainder $3.7 \%(n=1)$ were mixed-methods. This shows that research on paediatric pain management in LMICs has been predominantly quantitative considering that less than threequarters of the reviewed studies used a qualitative approach to study nursing management of pain in children and PPM education.

First, this review sought to identify the competencies about PPM taught to undergraduate nursing students and the gaps in the competencies taught. Six papers $(22.2 \%)$ were published on the knowledge and attitudes for PPM among finalist undergraduate nursing students, but none of these studies described the competencies taught to nursing students. A deficit of PPM competency among finalist nursing students was revealed. Identified concerns were mainly relating to the assessment of pain in children and the pharmacological and nonpharmacological management of pain, suggesting a rigorous examination of the content of PPM in the undergraduate nursing curriculum and how it is implemented in LMICs. Literature indicated that in the western context, there are proposed core competencies for pain management to be incorporated in the curriculum of a nursing undergraduate program and that the graduating nurse student should possess these competencies before entering the profession $(46,47)$.

Second, regarding the factors influencing the capacity of nurses educators and preceptors to facilitate nursing students acquiring competency for PPM, there was a dearth of literature focusing on this topic. Only one explored the ability of nurse educators and preceptors to facilitate nursing students learning about PPM (44). The other reviewed studies reported on factors affecting PPM in a clinical setting which also are thought to impact on students' learning practice on PPM during their clinical placements. One study (38) explored the factors that promote effective management of pain in children and indicated that timely provision of care by medical and nursing staff and involvement of children and their parents/ caregivers is important to facilitate efficient pain assessment and management. It was also highlighted that nurses' role of educating and providing support would greatly contribute to the effective management of pain in children. Equally, the collaboration of parents/caregivers and children with functional communication is crucial for students' learning practice of PPM under the facilitation of nurses in the paediatric ward. Similar factors were also described as facilitators of effective management of paediatric pain by nurses in a study conducted in England (48), which indicates that nurses from both LMICs and HICs have the same understanding of what would help them to effectively manage paediatric pain.

However, when considering the hindrances of effective PPM, several issues were identified in the current literature review. The most common issues across the LMICs including nurses' competency deficit for PPM, lack of autonomy in decision making, lack of pain assessment and pain management resources, cultural beliefs, and children's and parents characteristics. Although similar issues have been identified as barriers to PPM in HICs, they were not classified in the top seven in the findings from a study done by Czarnecki and co-authors (48), while the factors hindering the optimal management of paediatric pain were categorised as factors relating to staff (including lack of knowledge), factors relating to the children and parents, and organisational factors (including insufficient resources) (49). These issues are pertinent to the facilitation of undergraduate nursing students for their learning about PPM when attending clinical placement as well. It is understood that for learning to take place, nursing students should be in a conducive learning environment which requires competent and confident facilitators, and adequate resources. Previous studies conducted in western countries 
pointed out the challenges to pain education in undergraduate nursing programs which comprised curricula with content limited to basics on pain management, faculty with inadequate knowledge to teach pain content, limited collaboration with clinicians, and limited resources $(16,18)$.

Third, the reviewed studies highlighted the need to educate, empower, and support nurses with resources that permit them to provide optimal care to children with pain. Although the focus was not only on nurses in academia, it is thought that the identified strategies for improving nursing competency for PPM in clinical settings can also be applied to them and contribute to the capacity of educators and nurses in clinical settings to facilitate nursing students learning about PPM. The current review mirrored a need to improve paediatric pain education either in pre-registration and through in-service training to respond to the issue regarding deficit in competency for PPM. A review of nursing curricula of undergraduate programs was explicitly highlighted in four studies in which the authors suggested to determine the required PPM competencies before the nursing student graduates, how those competencies could be taught at school and reinforced during clinical placement. That is the required curricula revision should encompass reviewing the content, the teaching strategies that should include innovative approaches and the teaching plans taking into account the required time to cover the topic of PPM and the length of clinical placement. This was congruent with previous studies that reported an analysis of pain curricula and suggested solutions for improving pain education through proper curricula design, delivery and competency-based outcomes (17).

Continuing in-service training on PPM was mentioned as crucial to increase the competency and respond to the challenge of limited knowledge and inappropriate attitudes for PPM reported in most of the reviewed studies conducted in LMICs. Continuing education is also important for faculty and other nurses who participate in formal and informal education of nursing students. Researchers in western countries indicated that nurse educators and nurses, in general, should possess knowledge and skills accompanied with adequate attitudes toward PPM that enable them not only to effectively assess and manage pain in children (50), but also to provide optimal facilitation of nursing students to acquire competency in preparation to their professional practice $(16,19)$.
According to Voshall and co-authors (2013) (19), faculty who had more continuing education in pain management and more classroom time teaching pain management score better on KASRP and reported teaching pain management guidelines in the classroom than their counterpart with less continuing education.

Furthermore, the current review of the literature suggested that nurses in LMICs should be empowered through access to adequate resources and the support from the leadership for the effective management of pain in children. We understand that it is also valid for nurse educators to be able to provide effective facilitation for PPM competency acquisition by nursing students. The managers of institutions are called to secure required resources including human resources, pain assessment equipment, and supplies to optimise PPM. Also, structure reorganisation should be considered by the leaders to promote collaborative practice toward PPM. Previous studies have also shown similar strategies to improve pain education where availability of resources was identified as a key element (16), and interprofessional education as an approach to promote shared decision making toward PPM practices among healthcare professionals (17).

Lastly, the current review identified limited evidence on the facilitation of nursing students' facilitation to learn about PPM, suggesting the need for more research on paediatric pain education in the context of LMICs. Previous studies have focused mainly examining the competency of nursing students or nurses in clinical setting and factors influencing PPM, but very few $3.7 \%(n=1)$ studied on the competencies for PPM of nurses educators, especially nursing faculty and clinical instructors who are the pillars of nursing education. Comparatively, research in HICs indicated that competency of educators and leaders in pain education was part of the educational process (17). Students' knowledge may reflect what is retained, however, it is also important to recall the crucial role of knowledgeable faculty members and clinical mentors in disseminating information about pain management principles to students as stated by Lasch et al. (11).

\section{Limitations of the review}

This review did not report on a methodological quality appraisal of the reviewed studies because it was not part of the review process. However, to ensure consistency of the process and relevance of studies, one author 
(P.U.) performed the literature search, data extraction and data synthesis and checked with others authors (D.M., O.A., Y.B.M., \& B.U.). Although the focus of the review is on facilitation of nursing students acquiring competency for PPM, studies on factors influencing PPM were included as long as those factors can impact on teaching and learning about PPM. Also, the current review included only studies published in English, the number of reviewed studies may have been limited by the language of publication, therefore these findings may not reflect the whole scope of knowledge regarding nurse educators and preceptors facilitating student learning about PPM in LMICs.

\section{CONCLUSION}

Findings of this scoping review suggested that more research is needed on PPM education in LMICs, particularly concerning the capacity of nurses facilitating nursing students' acquisition of competencies for PPM. Although the current review identified a dearth of literature on the facilitation of nursing students' learning about PPM in LMICs, factors such as knowledge deficiency and inappropriate attitudes toward PPM, lack of autonomy in decision making, scarcity of resources and cultural misconception regarding pain in children were common hindrances of the effective PPM in LMICs. Nursing program curricula review, continuous inservice training, access to resources and the leadership support were identified as the main strategies to deal with those hindrances. Further research is required as a body of evidence to support the development of a framework for capacity enhancement of nurse educators and nurse preceptors who facilitate nursing students acquiring competency for PPM.

Acknowledgement: P.U. was supported by funding from Global Affairs Canada through Western University under its Training Support Access Model for Maternal, New-born and Child Health in Rwanda (TSAM) project.

Conflicts of interest: None.

\section{REFERENCES}

1. Ramira ML, Instone S, Clark MJ. Pediatric Pain Management? An Evidence- Based Approach. Pediatr Nurs. 2016;42(1):39-49.

2. Marshall C, Forgeron P, Harrison D, Young NL. Exploration of nurses ' pediatric pain management experiences in rural hospitals? A qualitative descriptive study. Appl Nurs Res [Internet]. 2018;42(December 2017):89-97.
A v a i 1 a b 1 e

$\mathrm{f} \mathrm{r}$ o $\mathrm{m}$ :

https://doi.org/10.1016/j.apnr.2018.06.009

3. Clark L. Pain Management in the Pediatric Population. Crit Care Nurs Clin NA [Internet]. 2011;23(2):291-301. Available from: http://dx.doi.org/10.1016/j.ccell.2011.04.003

4. Schellack N, Matimela M. Paediatric pain management. South African Fam Pract. 2016;58(3):42-7.

5. Twycross A. Guidelines, strategies and tools for pain assessment in children. Nurs Times. 2017;113(5):18-21.

6. Amponsah AK, Kyei-dompim J, Kyei EF, Oduro E, Afaya RA, Ahoto CK. Final Year Nursing Students ' Knowledge and Attitudes regarding Children' $s$ Pain. Pain Res Manag. 2020;2020:1-6.

7. Laprise J. Identification of Student Nurses ' Knowledge and Attitudes Regarding Pediatric Pain Management [Internet]. University of Connecticut; 2016. Available from: https://opencommons.uconn.edu/usp_projects/2 8

8. Latchman J. Improving Pain Management at the Nursing Education Level: Evaluating Knowledge and Attitudes. J Adv Pract Oncol. 2014;5(1):10-6.

9. Omari O Al. Knowledge and attitudes of Jordanian nursing students toward children ' $\mathrm{s}$ pain assessment and management? A crosssectional study. J Nurs Educ Pract. 2016;6(3):51-8.

10. Chiu LH, Trinca J, Lim LM, Tuazon JA. A study to evaluate the pain knowledge of two subpopulations of final year nursing students: Australia and Philippines. J Adv Nurs. 2003;41(1):99-108.

11. Lasch K, Greenhill A, Wilkes G, Lee M, Blanchard R. Why Study Pain? A Qualitative Analysis of Medical and Nursing Faculty and Students ' Knowledge of and Attitudes to Cancer Pain Management. J Palliat Med. 2002;5(1):57-71.

12. Alreshidi N. The impact of an interactive educational programme on children's nurses' knowledge, attitudes, beliefs and perceptions of children's pain, self-efficacy, and perceptions of barriers to optimal post-operative pain management in children. 2016 Dec 11 [cited 2019 Oct 16]; Available from: http://usir.salford.ac.uk/id/eprint/40987/\#.XacO 2b6fnoA.mendeley

13. Löfmark A, Thorkildsen K, Råholm M-B, Natvig GK. Nursing students' satisfaction with supervision from preceptors and teachers during clinical practice. Nurse Educ Pract [Internet]. 2012 May 1 [cited 2019 Oct 15];12(3):164-9. A v a i 1 a b 1 e f $r$ o m : https://www.sciencedirect.com/science/article/a bs/pii/S1471595311001867?via\%3Dihub

14. Phuma-Ngaiyaye E, Bvumbwe T, Chipeta MC. Using preceptors to improve nursing students ' 
clinical learning outcomes?. A Malawian students ' perspective. Int J Nurs Sci [Internet]. $2017 ; 4(2): 164-8$. Available from: http://dx.doi.org/10.1016/j.ijnss.2017.03.001

15. Kim KH, Lee AY, Eudey L, Dea MW. Improving Clinical Competence and Confidence of Senior Nursing Students through Clinical Preceptorship. Int J Nurs. 2014;1(2):183-209.

16. Campbell E. Faculty Perspectives of Teaching Pain Management to Nursing Students. Pain Manag Nurs [Internet]. 2019;(xxxx). Available f $r \begin{array}{lll}\mathrm{r} & \mathrm{o} & \mathrm{m}\end{array}$ https://doi.org/10.1016/j.pmn.2019.07.010

17. Thompson K, Johnson MI, Milligan J, Briggs M. Twenty-five years of pain education researchwhat have we learned? Findings from a comprehensive scoping review of research into pre-registration pain education for health professionals. Pain. 2018;159(11):2146-58.

18. Watt-Watson J, Murinson BB. Current challenges in pain education. Pain Manag. 2013;3(5):351-7.

19. Voshall B, Dunn KS, Shelestak D. Knowledge and attitudes of pain management among nursing faculty. Pain Manag Nurs. 2013;14(4):e226-35.

20. Arksey H, O'Malley L. Scoping studies: towards a methodological framework. Int J Soc Res Methodol. 2005;8:19-31.

21. Worl Bank. World Bank Country and Lending Groups [Internet]. Available from: https://datahelpdesk.worldbank.org/knowledge base/articles/906519-world-bank-country-andlending-groups

22. Mathew PJ, Mathew JL, Singhi S. Knowledge, attitude and practice of pediatric critical care nurses towards pain: Survey in a developing country setting. J Postgrad Med. 2011;57(3):196-200.

23. Freitas GRM De, Castro Jr CG De, Castro SMJ, Heineck I. Degree of Knowledge of Health Care Professionals About Pain Management and Use of Opioids in Pediatrics. Pain Med. 2014;15:807-19.

24. Dongara AR, Shah SN, Nimbalkar SM, Phatak AG, Nimbalkar AS. Knowledge of and Attitudes Regarding Postoperative Pain among the Pediatric Cardiac Nursing Staff: An Indian Experience. Pain Manag Nurs. 2015;16(3).

25. Gadallah MAE, Hassan AM, Shargawy SAE-H. Undergraduate nursing students ' knowledge and attitude regarding pain management of children in Upper Egypt. J Nurs Educ Pract. 2017;7(6):100-7.

26. Miftah R, Tilahun W, Fantahun A, Adulkadir S, Gebrekirstos K. Knowledge and factors associated with pain management for hospitalized children among nurses working in public hospitals in Mekelle City, North Ethiopia? cross sectional study. BMC Res Notes. 2017;2-7.

27. Amponsah AK, Oduro E, Bam V, Kyei-Dompim J, Ahoto CK, Axelin A. Nursing students and nurses' knowledge and attitudes regarding children's pain: A comparative cross-sectional study. PLoS One. 2019;14(10):1-12.

28. Kholowa ET, Chimwaza AF, Majamanda MD, Maluwa AO. Nurses ' Knowledge and Attitudes towards Pain Management in Children Admitted in the Paediatric Department of Queen Elizabeth Central Hospital, Blantyre, Malawi. J Biosci Med. 2017;5(6):46-59.

29. Ortiz MI, Ponce-Monter HA, Rangel-Flores E, Castro-Gamez B, Romero-Quezada LC, O'Brien JP, et al. Nurses' and Nursing Students' Knowledge and Attitudes regarding Pediatric Pain. Nurs Res Pract. 2015;2015:1-8.

30. Alotaibi K, Higgins I, Chan S. Nurses' Knowledge and Attitude toward Pediatric Pain Management: A Cross-Sectional Study. Pain Manag Nurs. 2019;20(2):118-25.

31. Jin Z. Knowledge and attitude of health care workers at Kenyatta National Hospital on pain assessment and management in children. 2015 ; (February). Available from: http://erepository.uonbi.ac.ke/handle/11295/94 341

32. Aydın B, Bektaş M. Pediatric Pain Management Knowledge Levels of Intern Nursing Students. Pain Manag Nurs. 2019; (xxxx).

33. Ekim A, Ocakc1 AF. Knowledge and attitudes regarding pain management of pediatric nurses in Turkey. Pain Manag Nurs. 2013 Dec 1;14(4):e262-7.

34. Lunsford L. Knowledge and Attitudes Regarding Pediatric Pain in Mongolian Nurses. Pain Manag Nurs. 2015;16(3):346-53.

35. Bawa M, Mahajan JK, Aggerwal N, Sundaram J, Rao KLN. Barriers to pediatric pain management in children undergoing surgery: A survey of health care providers. J Pain Palliat Care Pharmacother. 2015;29(4).

36. dos Santos MZ, Kusahara DM, Pedreira M da LG. The experiences of intensive care nurses in the assessment and intervention of pain. Rev Esc Enferm USP. 2012;46(5):1073-80

37. Amponsah AK, Kyei EF, Agyemang JB, Boakye $\mathrm{H}$, Kyei-dompim J, Ahoto CK, et al. NursingRelated Barriers to Children ' $\mathrm{s}$ Pain Management at Selected Hospitals in Ghana? A Descriptive Qualitative Study. Pain Res Manag. 2020;2020:1-7.

38. Aziznejadroshan P, Alhani F, Mohammadi E. Experiences of Iranian Nurses on the Facilitators of Pain Management in Children? A Qualitative Study. Pain Res Treat. 2016;2016:1-7.

39. Aziznejadroshan P, Alhani F, Mohammadi E. Experience of nurses about barriers to pain management in pediatric units? A qualitative study. J Nurs Midwifery Sci. 2017;4(3):89-96.

40. Mediani HS, Duggan R, Chapman R, Hutton A, Shields L. An exploration of Indonesian nurses' perceptions of barriers to paediatric pain management. J Child Heal Care [Internet]. 2017 Sep 23 [cited 2019 Sep 18];21(3):273-82. 
A v a i l a b l e f r o m : http://journals.sagepub.com/doi/10.1177/13674 93517715146

41. Clancy MA. Difficulty, despair and hope - an insight into the world of the health professionals treating paediatric pain in sub-Saharan Africa. J Res Nurs. 2014;19(3):191-210.

42. Dongara AR, Nimbalkar SM, PhatakAG, Patel D $\mathrm{V}$, Nimbalkar AS. An Educational Intervention to Improve Nurses' Understanding of Pain in Children in Western India. Pain Manag Nurs [Internet]. 2017 Feb 1 [cited 2020 Mar 2];18(1):24-32. Available from: http://www.ncbi.nlm.nih.gov/pubmed/2796490 9

43. Huth MM, Gregg TL, Lin L. Education changes Mexican nurses' knowledge and attitudes regarding pediatric pain. Pain Manag Nurs. 2010;11(4):201-8.

44. Uwimana P, Mukamana D, Adejumo O, Babenko-Mould Y. Nurse Educators ' and Preceptors ' Ability to Facilitate Students ' Development of Skills for Pediatric Pain Management. In: 30th International Nursing Research Congress [Internet]. 2019. p. 1. A v a i l a ble f r o m : https://sigma.nursingrepository.org/handle/107 $55 / 18142$

45. Amponsah AK, Kyei-Dompim J, Bam V, Kyei FE, Oduro E, Ahoto CK, et al. Exploring the educational needs of nurses on children ' s pain management? A descriptive qualitative study. Nurs Open. 2020;(December 2019):1-9.

46. Herr K, St. Marie B, Gordon DB, Paice JA, WattWatson J, Stevens BJ, et al. An interprofessional consensus of core competencies for prelicensure education in pain management: Curriculum application for nursing. J Nurs Educ. 2015;54(6):317-27.

47. Mackintosh-franklin C. Pain? A content review of undergraduate pre-registration nurse education in the United Kingdom. Nurs Educ Today [Internet]. 2017;48:84-9. Available from: http://dx.doi.org/10.1016/j.nedt.2016.08.035

48. Czarnecki ML, Salamon KS, Thompson JJ, Hainsworth KR. Do barriers to pediatric pain management as perceived by nurses change over time? Pain Manag Nurs [Internet]. 2014;15(1):292-305. Available from: http://dx.doi.org/10.1016/j.pmn.2012.12.003

49. Twycross A, Collins S. Nurses' views about the barriers and facilitators to effective management of pediatric pain. Pain Manag Nurs. 2013;14(4):e164-72.

50. Stanley M, Pollard D. Relationship Between Knowledge, Attitudes, and Self-Efficacy of Nurses In the Management of Pediatric Pain. Pediatr Nurs. 2013;39(4):165-71

How to cite this article:

Uwimana P., Mukamana D., Adejumo O., Babenko-Mould Y., Umubyeyi B. Facilitation of nursing students' competency acquisition for paediatric pain management in low- and middle-income countries: a scoping review. Research Journal of Health Science, 2021, 9(1): 82-99 


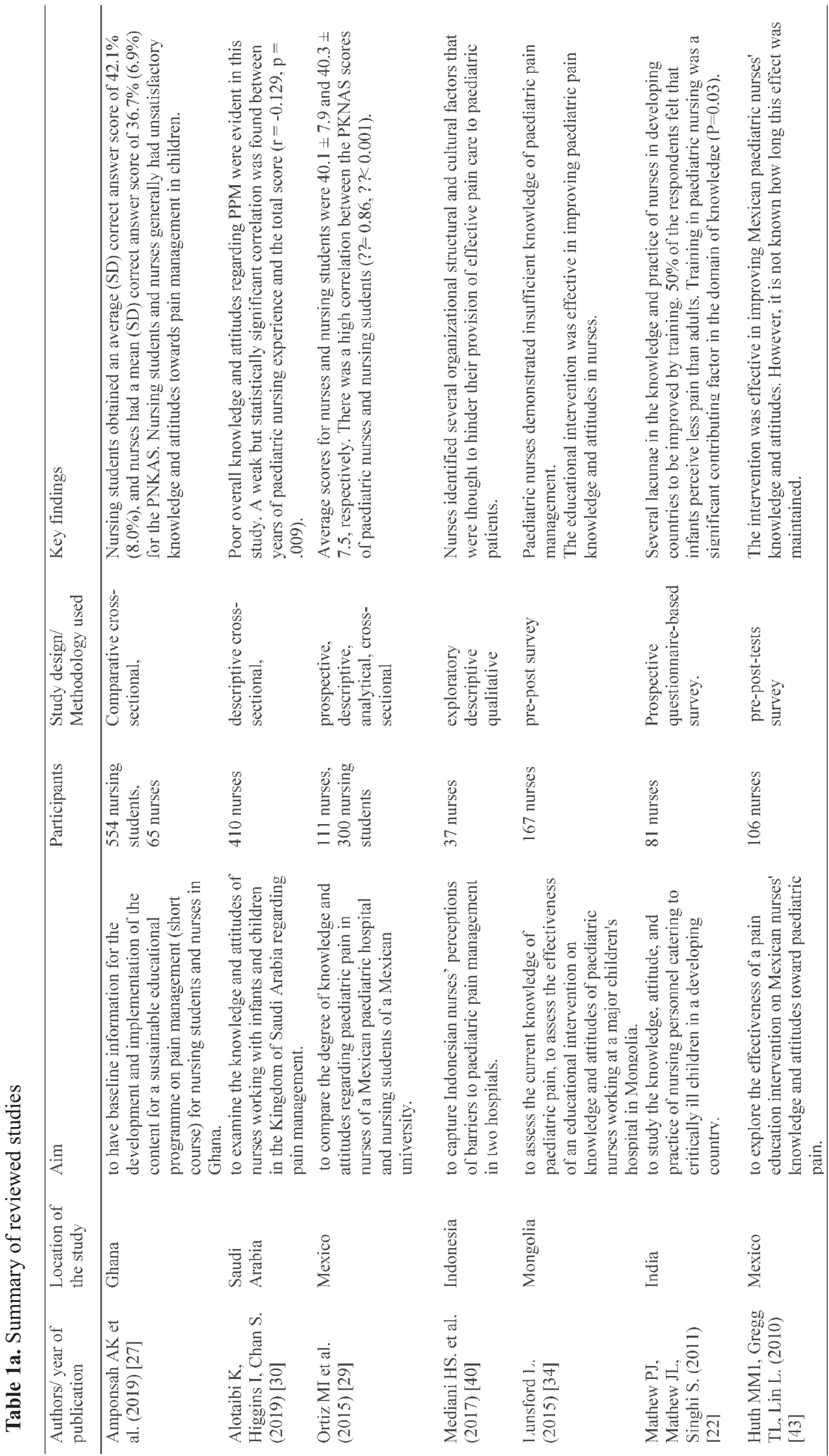




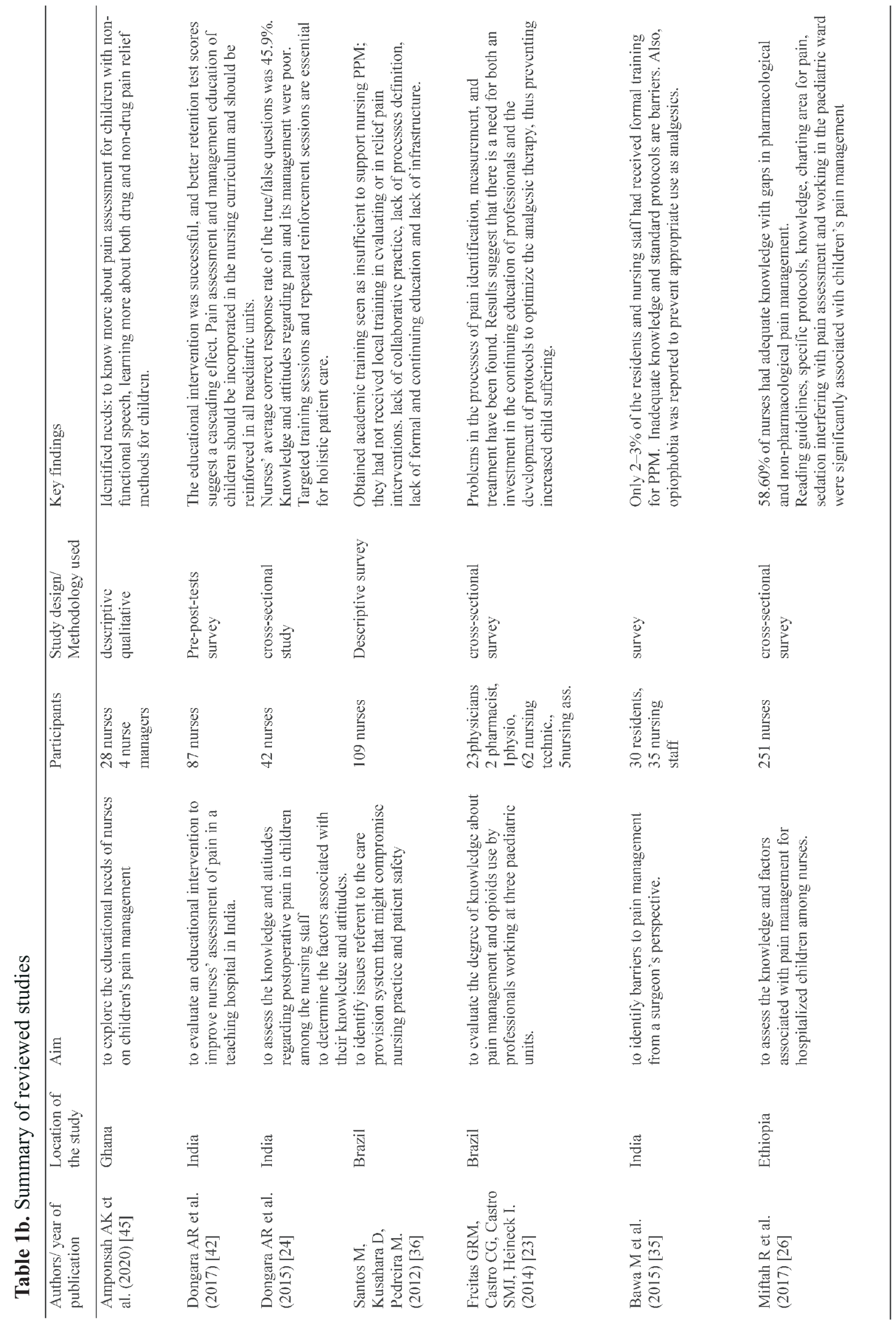




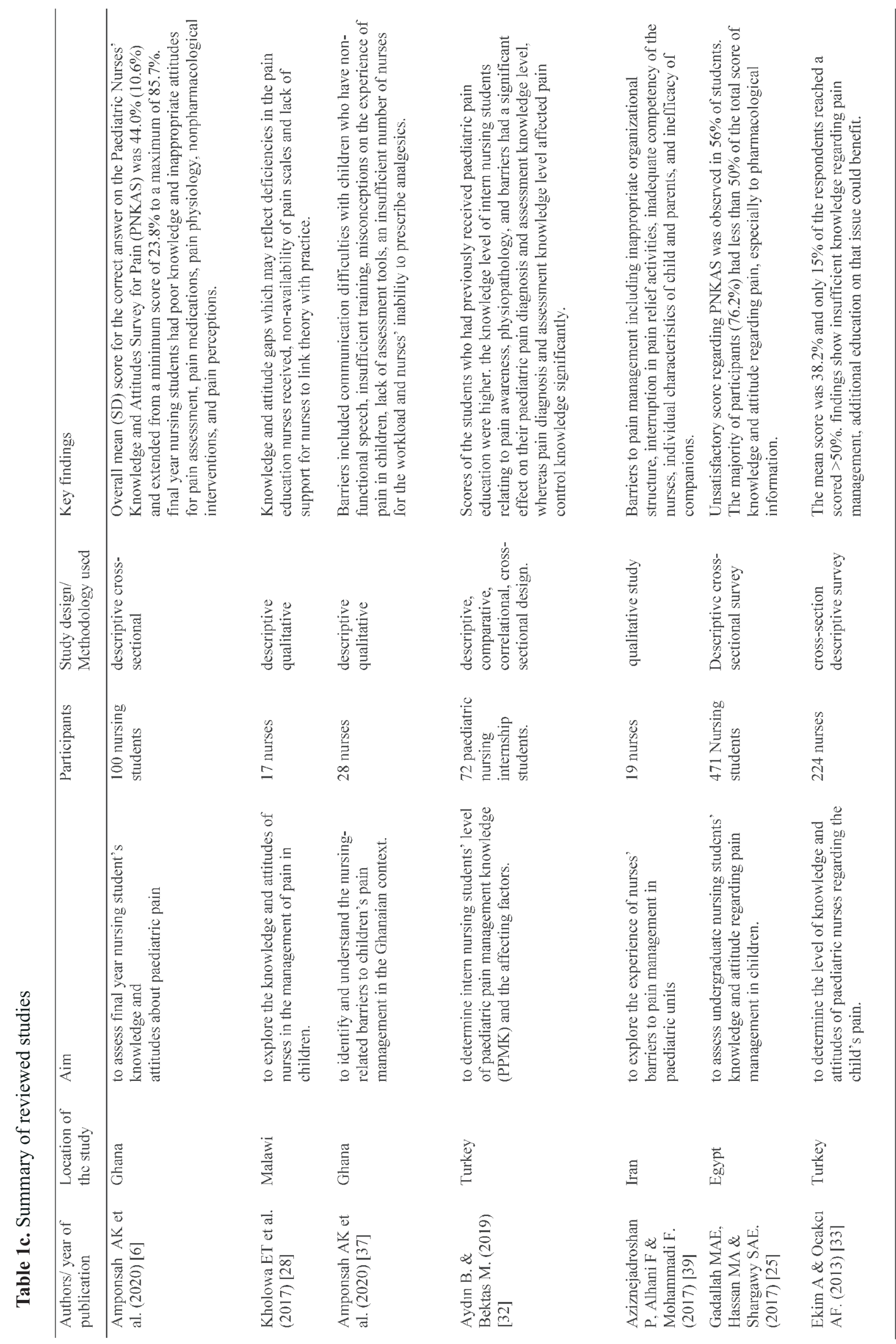




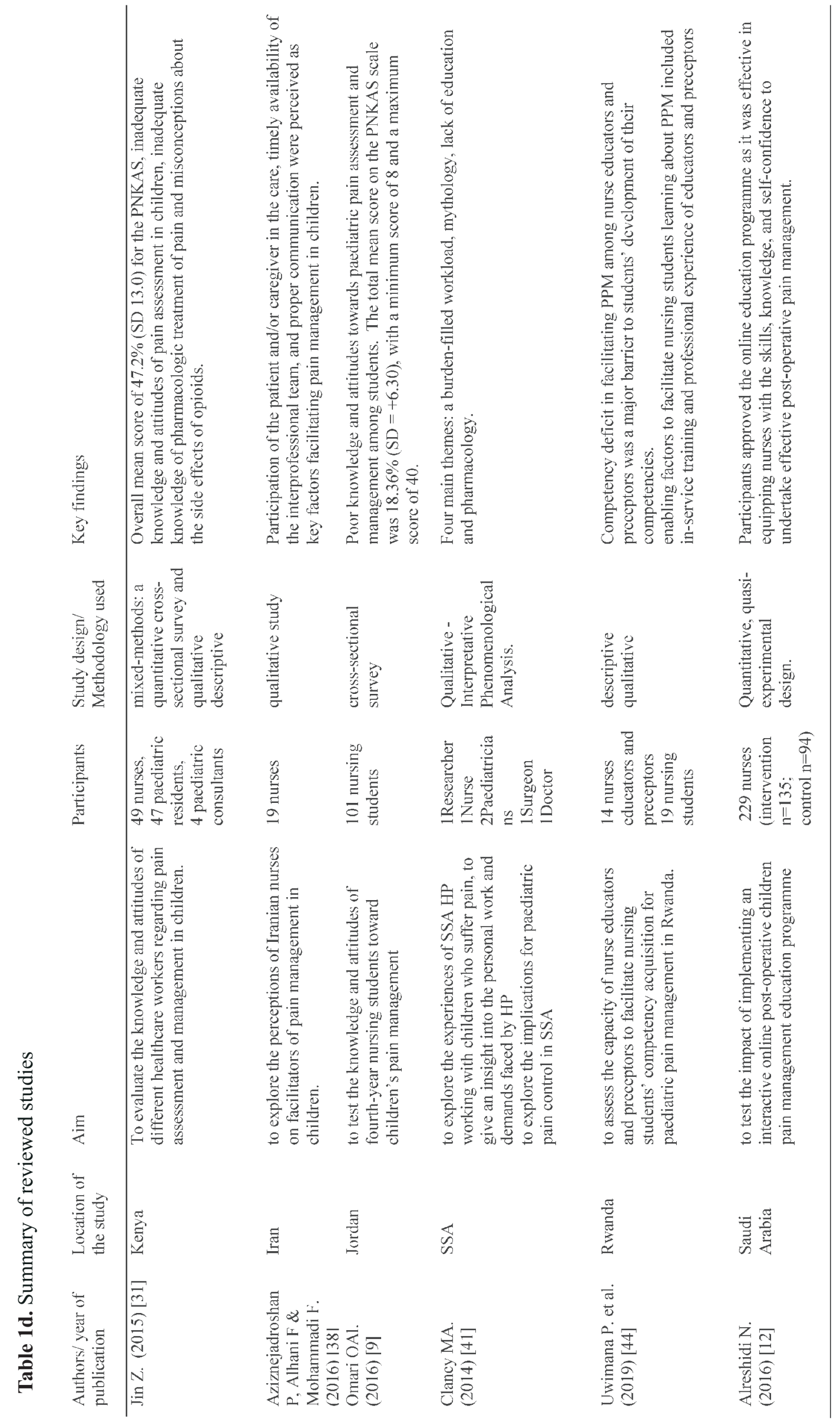

Res. J. of Health Sci. Vol 9(1), January/March 2021 


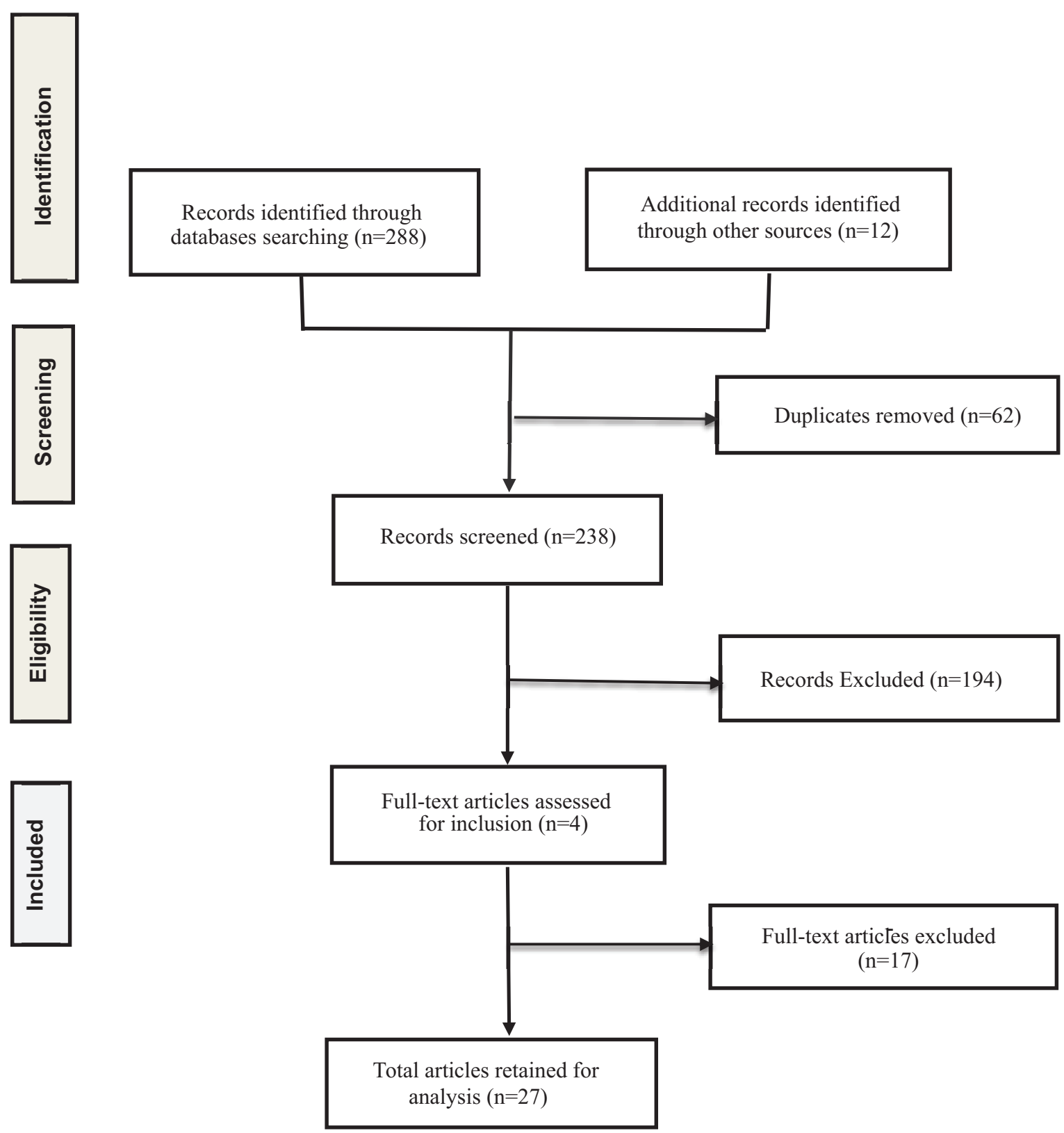

Figure 1: Flow chart for the selection process of the studies 


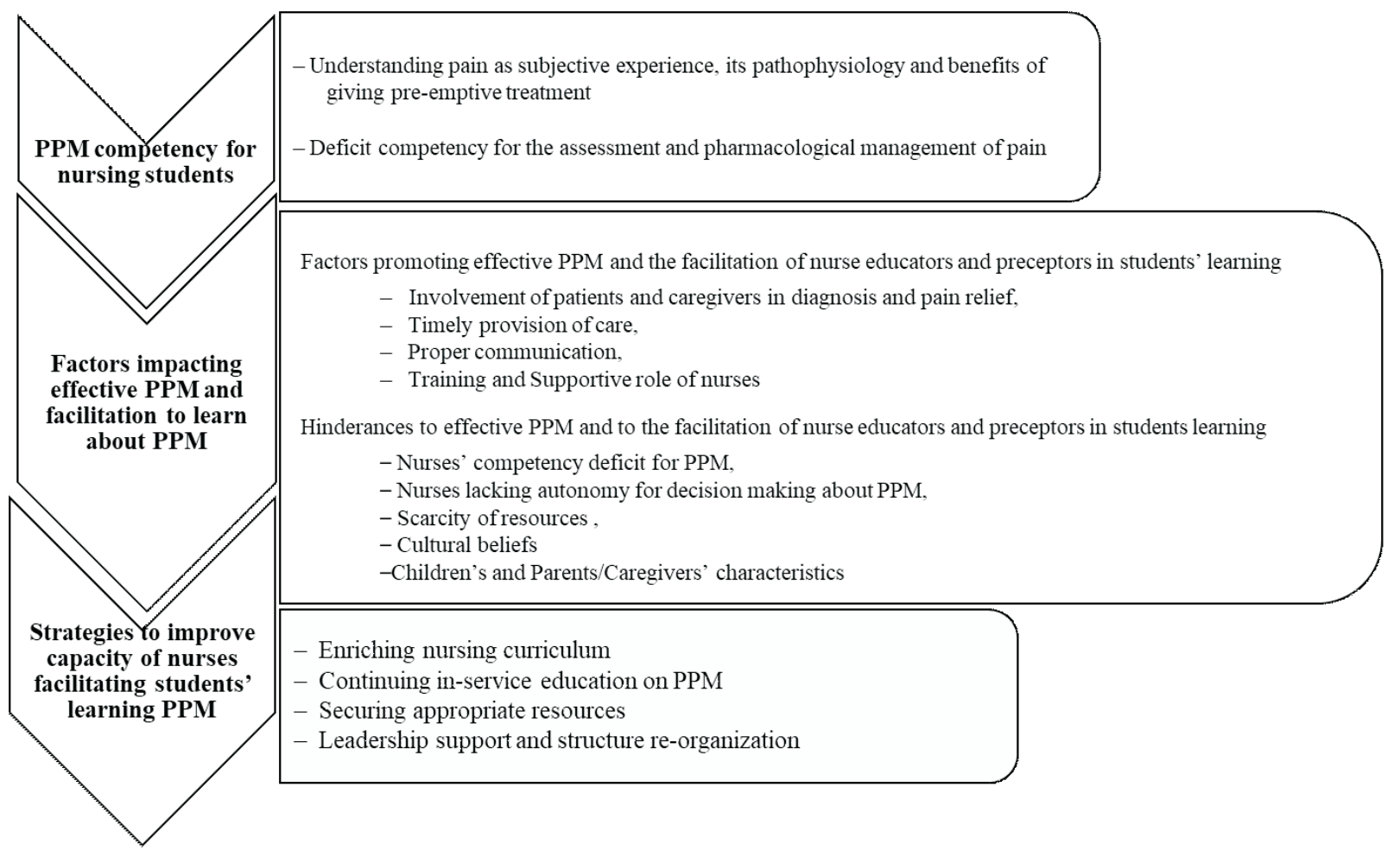

PPM, paediatric pain management

Figure 2: Visual representation of nursing students' PPM competency, factors affecting the facilitation to learn, and strategies for improving the capacity of educators and preceptors to facilitate student learning PPM. 